\title{
Disruptions from COVID-19: Challenges and Opportunities for Research Outputs in South African Higher Education
}

\author{
Kunle Oparinde \\ ORCID iD: https://orcid.org/0000-0003-2387-1258
}

\section{Vaneshree Govender \\ ORCID iD: $\underline{\text { https://orcid.org/0000-0003-0756-424X }}$}

\begin{abstract}
The novel Coronavirus Disease 2019 (COVID-19) has presented several challenges worldwide. Like other sectors of the world, institutions of higher learning equally have their own challenges which must be addressed in earnest to avoid severe disruption to the South African academic milieu. While there are many envisaged challenges, there are fairly possible opportunities to expect and the academic sector must be prepared. This chapter presents the possible challenges and opportunities for research outputs in South African Higher Education focusing specifically on the disruptions motivated by COVID-19. Using the indices spelt out in the 2015 policy on research outputs by the Department of Higher Education and Training, as well as the 2019 policy on creative outputs, the chapter discusses the envisaged challenges to research productivity in South Africa as a result of COVID-19. The study adopted the Knowledge Management Framework to address the possible opportunities from the COVID-19 situation. It was established that COVID-19 itself presents new research opportunities that researchers and stakeholders must consider.
\end{abstract}

Keywords: Coronavirus, higher education, research, innovation, opportunities 


\section{Introduction}

Academics and researchers in South African institutions of higher learning, following the COVID-19 (Coronavirus Disease 2019) pandemic, may be facing their biggest confrontation since the Department of Higher Education (DHET) introduced and prioritised research outputs in the 2003 Policy and Procedures for the Measurement of Research Outputs of Public Higher Education Institutions. For Luruli and Mouton (2016), the South African government has a longstanding tradition of supporting research at public higher education institutions. However, the COVID-19 outbreak, and its motivated disruption to several sectors, including the academia, presents imminent instability to research productivity in South Africa if not well managed. As such, disruptions from the pandemic suggest multidimensional consequences to higher education, and the research ambit of higher institutions is no exception. Albeit that the notion of disruption in South African higher education is not new given the history of student protests in the last few years, especially during the era of 'Fees Must Fall', the genre of this coronavirusmotivated disruption is however distinctive as it brings with it such concepts as social distancing which implies limited physical interactions among humans.

Since the outbreak of the new coronavirus in Wuhan in 2019, it has spread across the entire world resulting in several deaths in many parts of the world. Virtually all continents of the world have had their share. The situation has motivated several countries to develop quick coping mechanisms with the aim of flattening the curve of the virus. From closure of airports, to reduced mobility, and to complete lockdown for an extended period, several nations in the world are attempting to curtail the adverse effects of the virus. The resulting coping mechanisms will no doubt affect several sectors of the world as not only does the virus have worrying effects on human lives, it is bound to affect the smooth running of the entire world. The United Nations (2020:2) reports that the virus has the potential to significantly slow down the global economy. In fact, as the virus situation is expected to affect all spheres of our lives, higher education is expected to also be affected.

Institutions of higher learning in South Africa have prioritised research outputs through an upward trajectory of research publications, innovative ideas and postgraduate graduations. In the DHET's Research Outputs Policy (2015: 4), research output is defined, 
as textual output where research is understood as original, systematic investigation undertaken in order to gain new knowledge and understanding. Peer review of the research is a fundamental prerequisite of all recognised outputs and is the mechanism of ensuring and thus enhancing quality.

The policy considers outputs such as in journals, books, and published conference proceedings which meet the criteria spelt out in the policy. Over the years, the DHET has awarded subsidies to universities who have through their researchers produced journal articles, books and proceedings that meet the criteria listed by the DHET. With such support and encouragement from the government, publishing scientific works has become a part of academic development in South African institutions. However, the policy alluded to omitted outputs produced by 'creations' which has thus necessitated the formulation of an additional Policy on the Evaluation of Creative Outputs and Innovations Produced by South African Public Higher Education Institutions (2017). This added Creative Outputs Policy (2017: 3) now includes 'other forms of scholarly outputs, specifically those from the creative and performing arts as well as innovations'. As such, reference to research outputs in this chapter includes the forms of outputs stated in the Research Outputs Policy of 2015 and the 2017 policy on Creative Outputs.

It is a general perception that research undertaken at higher institutions is tied to societal progress and development. Maphalla and Malan (2014:24) concede that higher education institutions play an essential role in producing scientific knowledge through applied research that will enhance the quality of life of the society and strengthen the economy. As such, research outputs from higher education institutions becomes increasingly important for the growth and development of the society and it is an area that needs utmost attention during this era of COVID-19 disruption. For several years, the notions that Higher Education is the major driver of the knowledge system which leads to economic development, and that universities are key to the development of a nation, have seen the DHET in South Africa invest heavily in research advancement. As such, it is important to counter the negative consequences from COVID-19 by preparing plans to mitigate the possible risks brought by the virus. Although fundamentally different from the COVID-19 situation, Jansen (2018) reckons that disruption, and the possible loss of weeks and months in the teaching calendar, threatens the future of the South African Universities. 
If the disruption to higher education systems blossoms, the giant strides made by academics and universities over the years may presumably face an earthquake in 2020. More than just interrupted learning, research productivity may also face its challenges as the research outputs components stated by the DHET rely heavily on a fully operational higher institution system. As with disruptions emanating from student protests, the disruption emanating from COVID-19 also has consequences, and such disruptions make it challenging for universities to deliver their services on time due to shortages in terms of staff needs, funds, and physical facilities (Ajadi 2010:20). While the disruption is inevitable, mitigating strategies must be developed to present fresh opportunities for research productivity in South African higher institutions. Just as the coronavirus has ripple effects on business sectors, it has equally dangerous effects on higher education and particularly, research productivity being the focus of this study. For job security, the United Nations has recommended an internationally coordinated policy response that can help lower the impact on global unemployment. Therefore, for research outputs in higher education to continue to grow, there is a significant need to manage the risks posed by the virus.

\section{Knowledge Risk Management Framework as Response to Disruption}

The Knowledge Risk Management (KRM) Framework is a general model used in strengthening knowledge management activities in the context of achieving organisational excellence. According to Massingham (2010: 466), KRM is an emerging field of academic enquiry that intersects the fields of Risk Management (RM) and Knowledge Management (KM). RM is defined as an approach or framework of choice in many disciplines, including health care, research, engineering design, and the insurance sector which relies on the best available forward projections of natural hazards and accidents. For KM, it is considered as a lifelong perspective of learning that promotes constant opportunities for skills development and learning, both formal and informal (Villalba 2006).

Massingham (2010) notes that KRM offers a solution to the difficulties associated with conventional risk management methods. He argues that the principal aim of KRM is to work better with the cognitive constraints that are 
presented in a complex environment by trying to reduce the risk of knowledge loss. Trkman and Desouza (2012: 5) define KRM

as a likelihood of any loss from an event connected with the identification, storage or protection of knowledge that may decrease the operational or strategic benefit of any party involved in the network.

Tantau and Paicu (2013) support this notion by arguing that since the ability of an organization to manage risks derives from its capacity to manage knowledge, KRM stands as a prerequisite for competitive advantage in managing knowledge within an organisation. It is within this context that this study draws strengths from KRM to address the risks presented by the COVID19 to the academic sector of South Africa, particularly the institutions of higher learning. Although Trkmana and Desouza (2012) state that the field of KRM is mainly of interest in the environments of information technology, project management, and organizational networks, its emphasis and concentration on knowledge and learning makes it applicable to the education sector.

Conceptually, KRM is created to manage knowledge even better by ensuring measures to retain and protect knowledge effectively in order for organisations to continue to survive competitively. Tannenbaum and Alliger (2000) provide a systematic approach model towards management of knowledge by dividing them into four components namely: knowledge sharing, knowledge accessibility, knowledge assimilation and knowledge application. These four components share affinity with this study in that research outputs and knowledge production are intertwined. The production of any form of research output is an attempt made by a researcher or a group of researchers to share knowledge. As such, the knowledge becomes accessible to wide variety of audience who assimilate the findings and apply or reproduce based on the researchers' ideas. For higher institutions to mitigate the disruptions which present risks to production of knowledge as a result of the COVID-19 virus, the KRM framework becomes useful. Hence, issues that are pertinent to knowledge production such as the sharing of knowledge; accessibility of knowledge; assimilation of knowledge; and application of knowledge are efficiently addressed in order to continue to advance research productivity in South African higher institutions in spite of the motivated disruption by the novel coronavirus. 


\section{Reflections on COVID-19 and Possible Challenges to Research Outputs in South African Higher Education}

Coronavirus and its motivated disruptions have constructed a redirection for the entire world to pursue. In fact, many country leaders have used war-like terms to explain the battle their countries are fighting with regards to the virus. President Cyril Ramaphosa of South Africa declared that the country is in a national state of disaster. On the education sector, the impact of COVID-19 on South African higher education institutions has forced a rethink of the traditional approach to teaching and learning. The disruption brought by the virus has compelled an aggressive overhaul of educational activities and so should research and innovation be overhauled. As such, this has brought to the fore an emphasis on what the situation implies for the higher education sector in South Africa. The situation has brought about some response strategies to the disruptions brought by the virus especially by transforming and migrating educational activities from face to face to online platforms. For this study, the focus is on research productivity in higher education, and the research outputs indices outlined by the DHET form the backdrop for the discussion. Put more explicitly, how research outputs in South Africa can continue to maintain its upward trajectory despite the disruption is of interest.

An upward trajectory of research publications has been the hallmark of many institutions of higher learning in South Africa in the past years. This is unsurprising when one considers the notion that knowledge production is the pinnacle of institutions of higher learning, and the DHET has encouraged research productivity by providing financial resources and incentives. An opinion also shared by Chiware and Skelly (2016:1) that research publications have become a national norm for researchers in South African tertiary education institutions to publish, and publishing is part of the performance management and promotion criteria of several institutions on the African continent. In fact, on the African continent, South Africa is the highest producer of publications (Chiware \& Skelly 2016). In the current year, due to the disruptive nature of coronavirus, possible risks facing research outputs must be mitigated if South Africa hopes to continue to lead in research publications.

The lockdown has significantly affected the availability of resources for researchers. With restricted movements, institutions of higher learning were shut down. This poses some challenges for researchers who rely on 
resources such as laboratories, university internet access and on-site university subscriptions. Tho and Yeung (2016:97) also affirm that scientists need to carry out experiments to test theories, whereas students need to conduct experiments to understand the theories, and as such, 'laboratories are essentially simulation environments where one can create various experiments and learning experiences'. In another study, Ghavifekr et al. (2017:41) establish that the lack of access to institutional resources is a complex challenge facing researchers across the world. The situation created by the coronavirus is severe for researchers in need of physical university resources to produce research outputs. While most scientists rely on laboratory work, others rely on university library access where materials are made available for free or at a low cost, and many others rely on university internet access. What becomes a challenge therefore is that an inability to access these facilities puts a burden on the productivity of researchers nationwide and quickly, there is a need to respond with a strategy. Such challenges are also likely to be faced by researchers whose outputs are creative. Artists, sculptors, actors, directors, cinematographers all alluded to in the 2017 Creative Outputs policy who need studios or locations for their outputs also face similar challenges as those who use laboratories. The situation affects everyone in some ways and it is necessary to prepare response strategies.

Furthermore, there might be challenges for field researchers whose methods include observations, interactions and understanding of people in their natural environment. For Prew and Lin (2019), field experiments, like scientists in the laboratories, are also fraught with their own challenges. They intimate that such challenges include environment set-up and participation rates. With the declarations on restricted movement and social distancing, it is appropriate to assume that researchers may encounter challenges in visiting their fields for research purposes and as such unable to collect data for research publications. These sorts of uncertainties make it more challenging for academics and potential participants to be entirely committed to the research process. It is an undisputable fact that commitment on the part of the researcher and research participants is a vital element to a research project's success, as this certainly affect the success or failure of the project (Ghazinejad, Hussein $\&$ Zidane 2018). It is also noteworthy to mention that considering the ethical requirements in research, it is only right that participants partake only in studies in which they have consented to. At a time when people are generally careful and unsettled due to the coronavirus situation, field researchers are further 
likely to encounter challenges gathering participants. In this case, the use of technology has to be incorporated into data collection. The envisaged challenge however is whether research participants are able to perform effectively using online and virtual platforms and whether data collected online can be as efficient as those collected in the natural settings.

Reflections are also made on postgraduate studies. The postgraduate study is often the stage where researchers are trained as it provides an ideal opportunity for emerging researchers (Oparinde \& Govender 2019). Having recognised this, established researchers have, over the years, collaborated with their postgraduate students in producing research publications. Also, institutions of higher learning have identified the importance of postgraduate students. As a result, these institutions attempt to attract as many postgraduate students as possible, for example through funding opportunities and tuition waivers. Also popular is that these institutions arrange for research capacity development programmes that will advance the research skills of the postgraduate students. Evidently, postgraduate students are essential to knowledge production in South African higher institutions.

As Larivie 're (2011:16) puts it, postgraduate students are an important part of the academic workforce and they contribute abundantly to the advancement of knowledge in their scientific discipline. He commends the essential role of postgraduate programmes, not only for the 'reproduction' of researchers, but also for the research system, since they contribute, during their studies, to a considerable proportion of the new knowledge being created. This is a credible position in South African higher education where postgraduate students are known for collaborating with their mentors/supervisors to publish academic papers following the completion of their research thesis. However, as important as postgraduate students are, the disruption to higher education resulting from coronavirus may also pose some challenges for postgraduate research. decrease in the completion rates of postgraduate students when one considers the array of challenges the disruption brings with it. As with independent researchers, postgraduate students also face the possible challenge of a limited availability of resources during this period as resources required to complete their research and writings may not be readily available at their disposal.

In fact, with everything at a standstill at the initial stage of the virus in South Africa, capacity building initiatives by institutions of higher learning in South Africa were interrupted until online training programs became popular 
as a response strategy by many institutions. Since the total shutdown came rather abruptly, and institutions were not prepared for it in South Africa, it is safe to assume that many of these capacity building initiatives were at some point paused or disrupted, thus leading to reduced/delayed learning opportunities for postgraduate students. Especially for fresh postgraduate students, the importance of such capacity building initiatives cannot be underscored when one considers the roles of such initiatives in strengthening postgraduate students and enhancing their research capacity.

The disruption brought by the virus also saw a paucity in intellectual gatherings with some events cancelled while others were rescheduled or accommodated virtually. Beyond just a mere presentation, intellectual gatherings, such as conferences, are an indispensable resource to academics the world over as it affords them the opportunity to network and interact with other established researchers in their fields of interest. Through conferences, symposia, workshops, and seminars, researchers have increased collaborative opportunities with colleagues from other academic institutions with similar and innovative research interests. According to Oester et al. (2017:1), a conference is not just an avenue for a scientist to present their research to the wider community, but it can be an important venue for brainstorming, networking and making vital connections that can lead to new initiatives, papers and funding, in a way that virtual, online meetings cannot.

Similarly, Parsons (2015) intimate that attending a conference is more than having face-to-face interactions with leaders in one's field, it is also a way to start collaborations on papers or projects, and to more directly advance one's career by finding new positions, or to build your programme by using these meetings to recruit faculty students or interns. What is obvious from is that the importance of conferences cannot be underestimated when it comes to the development of researchers, and consequently, their outputs. By having such intellectual discussions in intellectual gatherings, researchers with their varied expertise generate new initiatives leading to research publications such as books, articles, and proceedings, among others. Adversely, the pandemic nature of the coronavirus presents a possible danger taking into account the argument by Stevens et al. (2016), that if there is a drop-in conference attendance, there would be an inevitable decline in areas such as knowledge sharing, career development, and research collaboration.

For most researchers, the physical connection and networking at conferences is important in ways virtual conferences are unable to replicate. 
The imminent danger therefore is that without such gatherings, academics are unable to accrue the full benefits of conferences and it is evident that virtual or online conferences cannot fully actualise the purpose of face-to-face conferences as affirmed by (Oester et al. 2017). Having highlighted that intellectual gatherings are of main benefits to researchers, a complete lack of such events for academics in South African higher institutions would imply a drop-in collaboration rates, as well as a reduction in new initiatives that result in publications. However, this is not an option as it would have been imprudent to pause research and innovation activities until the aftermath of the virus. As a matter of fact, for productive South African academics, they are often encouraged to attend conferences through their research incentives in order to produce more research outputs. Despite the difficult situation putting restrictions on physical intellectual gathering, the use of virtual methods for conferencing is important and necessary if it is expected that research outputs would remain to grow in South Africa

The coronavirus pandemic may also present imminent problems for funding opportunities. One of the major drivers of research productivity is the availability of funding. Funding contributes to research productivity by providing resources for researchers to conduct their research works. Apart from this, they also provide support for postgraduate students, academic conferences, academic exchange, postdoctoral fellows and so on. While some of these funding bodies are government departments, others are independent bodies. Evidently, one cannot underemphasise the role of finance in research productivity. To Ebadi and Schiffauerova (2015), funding is one of the main determinants of scientific activities, and securing funding is one of the most important factors for a researcher, enabling him/her to carry out research projects. They contend that funding can influence the size and efficiency of research and development, as well as its productivity. In an akin view, Szaszi (2015) agrees that research can only exist with good and secure funding as it is a dominant part of investigators' activity. Szaszi argues vehemently that supporting research through funding is of utmost importance and is the best way to generate an environment of innovation in research.

Clearly, it is impossible to eliminate funding from research if significant outputs are expected. This explains the DHET's support for South African higher institutions through incentives as well as funding opportunities for research activities including travels. Currently, the coronavirus pandemic has seen government bodies allocate some emergency and unplanned funds to 
combat the pandemic. The envisaged economic effect of the lockdown presents a challenge for funding bodies who then need to reprioritise their funding allocations. This presents risks to funding opportunities in the aftermath of the coronavirus-motivated disruptions. While countries may be focusing on battling unemployment issues, they will equally be hoping to resuscitate from the possible economic meltdown resulting from loss of revenues during the lockdown. Research ambits in institutions of higher learning are also unlikely to avoid the wide economic effect of the disruption. However, research outputs are equally important for economic development implying that while trying to get the economy strong again, funding bodies must also be aware that prioritising the aspect of research and innovation is critical. Also, researchers who have developed research ideas from COVID-19 should begin to source for funds using different issues relating to the pandemic as their research focus.

\section{Capitalising on Opportunities for Research Outputs}

At a time when academics and researchers are faced with dilemma stemming from the nationwide lockdown in South Africa and disruption to academic activities, it is pertinent to discuss suggestions and recommendations on how to deal with the possible disruptions facing scientific publications in the country's higher institutions. It is of utmost importance for academics and researchers to devise a means to savour research outputs in order to continue to maintain the upward trajectory already in place in South African institutions. Importantly, as recommended by Christensen et al. (2018), one of the major ways of dealing with disruption is by aggressively investing in existing capabilities in order to slow or delay the onset of disruption. In the case of coronavirus, the disruption is with us. An aggressive strategy that invests in existing capabilities would indeed be relevant in combatting the possible implications stemming from the coronavirus-motivated disruption on higher education.

At current, it is rather challenging to establish the exact degree of effect the disruption may have on research productivity as this will best be examined in the near future. In fact, based on the dynamics involved in research, some disciplines (such as those that could rely on desktop studies) may witness increases in their research output while others (such as creative contributions) may see decreases. While this cannot be ascertained and is not the focus of this study, it is important nonetheless to build a system for research that is resilient 
to the disruption. Already, the situation has seen institutions of higher learning and stakeholders build a form of resilience in order to tackle the disruption. This is indeed an imperative strategy if institutions in South Africa intend to sustain research outputs and reduce the possible danger the coronavirusmotivated disruption brings to fore. An emergency response team to address the possible challenges that may face research productivity in South Africa is important for all institutions of higher learning.

The task of the emergency response team would be, among others, to revisit the issue of incentivisation of researchers if research productivity appears to be on the backfoot. As discussed earlier, researchers need to be further enticed with incentives so that they can develop innovative ways of increasing their outputs amidst the disruption. This strongly adheres with Christensen et al.'s (2018) suggestion to aggressively invest in existing ideas to deal with repelling the disruption. Secondly, researchers may be encouraged to redirect the focus of their research onto COVID-19. Essentially, they must be inspired to locate COVID-19 within their disciplines and sub-disciplines $v i z-a-v i z$ what impact the disruption has on these disciplines. The current coronavirus pandemic creates an open avenue for fresh forms of research publications, and academics must tap into this to maintain a progressive trajectory for research publications as it is still recent and contemporary.

Although it has been established that the DHET has invested funds into research productivity, it is even more important in the current state that more funds be injected for researchers to carry out their studies, especially those working on the convictions of COVID-19 given that journals and publishing houses are currently encouraging publications mirroring the pandemic. Research management bodies must develop innovative ways of getting funds for research, especially those targeting COVID-19 in academic disciplines. Finally, researchers must be tasked with embracing the Fourth Industrial Revolution (4IR) and injecting the concept into their research as it has become obvious that the era of digitalisation is upon us and to continue to keep up, especially with growth in research, 4IR has to take a more rightful position for new technologies to be able to process information faster, and as a result, drive economic growth, research outputs and other important sectors of the world. While the discussion presented here may not completely mitigate the effect of the disruption on research outputs, moving in the discussed directions would help significantly in diminishing the effect and preventing a reduction in research outputs in South Africa as a result of the COVID-19 pandemic. 


\section{Conclusion}

Worldwide, the coronavirus pandemic has caused havoc and it is lucid that the continued existence of the virus presents damaging effects for the world. While it is impossible to avoid the negative effects of the virus, it is feasible to have coping strategies in place to cushion the effect. As such, it becomes necessary for decision-makers to brainstorm on ideas that will reduce the hazardous effects of the virus. In higher education for instance, the ministry of education, universities and research management bodies must prepare for the aftermath by developing strategies to deal with the virus. Research outputs in South Africa have been on an upward trajectory for many years and it is important to maintain the momentum by putting strategies in place to mitigate the dangers brought by the COVID-19 disruption. This paper has discussed the potentially alarming effects of the virus on research outputs as well as the strategies to manage the threats of the disruption. To avoid a drop-in research outputs due to the disruption to higher education, the key elements involved in research productivity must be addressed. Importantly, COVID-19 should be considered as a research opportunity and focusing on research ideas pertaining to COVID-

19 would widen the scope and extent of research outputs in South Africa.

\section{References}

Ajadi, T.O. 2010. Private Universities in Nigeria: The Challenges Ahead. American Journal of Scientific Research 7: 15 - 24.

Chiware, E. \& L. Skelly 2016. Publishing Patterns at the Cape Peninsula University of Technology. South African Journal of Science 112,1/2: 1 6. https://doi.org/10.17159/sajs.2016/20140220

Christensen, C.M., R. McDonald, E.J. Altman \& J.E. Palmer 2018. Disruptive Innovation: An Intellectual History and Directions for Future Research. Journal of Management Studies 55,7: 1043 - 1067.

https://doi.org/10.1111/joms.12349

Department of Higher Education 2003. The Policy and Procedures for the Measurement of Research Output of Public Higher Education Institutions. Pretoria: Government Printers.

Department of Higher Education 2015. Research Outputs Policy. Available: https://libguides.wits.ac.za/ld.php?content_id=21220905 (Accessed 12 August 2020). 
Department of Higher Education 2017. Policy on the Evaluation of Creative Outputs and Innovations Produced by South African Public Higher Education Institutions. Available at:

https://www.uj.ac.za/research/Documents/Creative\%200uputs\%20Polic $\mathrm{y} \% 202017 . \mathrm{pdf}$ (Accessed on 12 August 2020.)

Ebadi, A. \& A. Schiffauerova 2015. How to Receive More Funding for your Research? Get Connected to the Right People! PloS One 10,7: 1 - 19. https://doi.org/10.1371/journal.pone.0133061

PMid:26222598 PMCid:PMC4519253

Ghavifekr, S., T. Kunjappan, L. Ramasamy \& A. Anthony 2017. Teaching and Learning with ICT Tools: Issues and Challenges. Malaysian Online Journal of Educational Technology 4,2: 38 - 57.

Ghazinejad, M., B.A. Hussein \& Y.J.T. Zidane 2018. Impact of Trust, Commitment, and Openness on Research Project Performance: Case Study in a Research Institute. Social Sciences 22,7: 1 - 11.

https://doi.org/10.3390/socsci7020022

Jansen, J. 2018. The Future Prospects of South African Universities Policy and Funding Options. Viewpoints 1: 1 - 13.

Larivie re, V. 2011. On the Shoulders of Students? The Contribution of PhD

Students to the Advancement of Knowledge. Available at: https://ost.openum.ca/files/sites/132/2017/06/Shoulders.pdf (Accessed on 13 April 2020).

Luruli, N.M. \& J. Mouton 2016. The Early History of Research Funding in South Africa: From the Research Grant Board to the FRD. South African Journal of Science 112,5/6: 1 - 6.

http://dx.doi.org/10.17159/sajs.2016/20150097

Maphalla, O.M. \& L. Malan 2014. The Implementation of the Research Output

Policy in South Africa: Challenges and Solutions. Administratio Publica 22,2: 5 - 27.

Massingham, P. 2010. Knowledge Risk Management: A Framework. Journal of Knowledge Management 14,3: 464 - 485.

https://doi.org/10.1108/13673271011050166

Oester, S., J.A. Cigliano, E.J. Hind-Ozan \& E.C.M. Parsons 2017. Why Conferences Matter - An Illustration from the International Marine Conservation Congress. Available at: https://doi.org/10.3389/fmars.2017.00257 (Accessed on 15 April 2020). 
Oparinde, K. \& V. Govender 2019. 'Postgraduateness' - A Project for Constructing a Renaissance Africa: A Decolonial Approach. Education as

Change 23: 1 - 18. https://doi.org/10.25159/1947-9417/5096

Parsons, E.C.M. 2015. So, you Think you Want to Run an Environmental Conservation Meeting? Advice on the Slings and Arrows of Outrageous Fortune that Accompany Academic Conference Planning. Journal of Environmental Studies and Sciences 5,4: 735 - 744.

https://doi.org/10.1007/s13412-015-0327-8

Prew, N. \& M. Lin 2019. The Benefits and Challenges of Conducting Field Experiments in Consumer Research. Available at:

https://methods.sagepub.com/case/benefits-and-challenges-of-

conducting-field-experiments-consumer-research (Accessed on 19 April 2020). https://doi.org/10.4135/9781526466518

Stevens, R., M. Bressler \& L. Silver 2016. Challenges in Marketing Academic

Conferences: A Pilot Study. Services Marketing Quarterly 37,3: 200 207. https://doi.org/10.1080/15332969.2016.1184545

Szaszi, K. 2015. A Basic Scientist's Reflections on Research Funding.

Canadian Journal of Kidney Health and Disease 50,2: 1 - 4. https://doi.org/10.1186/s40697-015-0087-0

PMid:26629356 PMCid:PMC4666045

Tannenbaum, S.I. \& G.M. Alliger 2000. Knowledge Management: Clarifying the Key Issues. Chicago: International Association for Human Resource Information Management.

Tantau, D.A. \& E.A. Paicu 2013. Managing Knowledge Risks in an Intrapreneurial Environment. The International Journal of Management Science and Information Technology 2: 4 - 9.

Tho, S.W. \& Y.Y. Yeung 2016. Technology-enhanced Science Learning through Remote Laboratory: System Design and Pilot Implementation in Tertiary Education. Australasian Journal of Educational Technology 32,3: 96 - 111. https://doi.org/10.14742/ajet.2203

Trkmana, P. \& K.C. Desouza 2012. Knowledge Risks in Organizational Networks: An Exploratory Framework. The Journal of Strategic Information Systems 21,1: 1 - 17.

https://doi.org/10.1016/j.jsis.2011.11.001

United Nations. 2020. Global Trade Impact on Coronavirus (COVID-19) Epidemic. Available at:

https://unctad.org/en/PublicationsLibrary/ditcinf2020d1.pdf 
Disruptions from COVID-19, and Research Outputs in S.A. HE

(Accessed on 10 April 2020).

Villalba, E. 2006. The Uniqueness of Knowledge Management in Small Companies. PhD dissertation, Stockholm University.

Kunle Oparinde Research Associate Durban University of Technology KunleO@dut.ac.za

Vaneshree Govender Manager (Acting) Research and Postgraduate Support Directorate Durban University of Technology vanesh@dut.ac.za 